\title{
Counter attack
}

$\mathrm{L}$ et's be honest: my life as a lawyer is one of unrelenting tedium. The days are long, the work is familiar, and my stash of quirky client stories is getting a bit thin. So when I was asked to do a bit of news investigation for $C M A J$ to see what it is like to buy levonorgestrel - Plan B - without a prescription, I hid my excitement, feigned detachment and immediately asked about an expense account.

The assignment: to buy the drug in a small, remote town where I was sojourning on business. If I could not get the pill in this straight-talking, hardworking place, who could? In fact, sensing that my assignment would be disappointing in its ease, I upped the stakes by inviting my workmates to walk with me to the drugstore for some snacks during a break. Since, like lawyers, young girls travel in packs, I reasoned that if I could obtain the drug without my colleagues discovering me, then a teenager desperate for privacy might also be able to escape detection.

Slipping away from the group, I approached a smiling pharmacy worker and asked for Plan B. "Plan B" is clearly a euphemism for nuclear attack, natural disaster or personal harm. Her
When I explained that I wanted Plan $\mathrm{B}$, Kevin refused to hand it over. Only a pharmacist could give me the drug. He was a pharmacist's assistant; the real pharmacist was on her break. I asked if I could see the form in advance to move things along. No go. I reckoned it must contain skill-testing questions; seeing them in advance would be cheating.

All of this was becoming entertaining for those around me. Not wanting to be discovered by my coworkers, I said I would come back later.

When I returned at 5:30, Kevin, the man of steely resolve, informed me that the pharmacist had left for the day. No pharmacist, no Plan B. Although I sensed Kevin was the kind of guy who would protect the system by throwing himself on the live grenade of a woman asking for Schedule II drugs, I persisted. Why, I wanted to know, could I not buy the drug without seeing a pharmacist first? Because I needed to answer the questions. What do the questions have to do with a nonprescription drug? I would understand when I saw the questions. Could I see the questions? Only a pharmacist could hand them out. Why is the pharmacy open when there is no pharmacist on duty?

\section{If a curmudgeon like me can't obtain}

\section{emergency contraception, what chance does a worried teenager have?}

smile vanished. Glancing around in panic for someone to handle this Code Red request, she muttered that I would have to speak to a pharmacist.

"Why?" I asked.

"Because you have to fill out a form."

What form, I asked. She wasn't sure. Where was the pharmacist? She wasn't sure. Could I speak to someone else? Spotting a white smock, she grabbed a tall young man - I'll call him Kevin — and beat a hasty retreat.
This exchange was beginning to cause a stir. Those customers furthest away drew closer. Those closest, backed away.

I forged ahead. (Don't forget how boring my life is.) Whose instructions was he following? A pharmacy association. Which one? He could not name it. Was this not a nonprescription drug. Yes. Why could I not purchase the drug if no prescription was necessary?

And then he said it:

"Because, ethically, I don't believe in

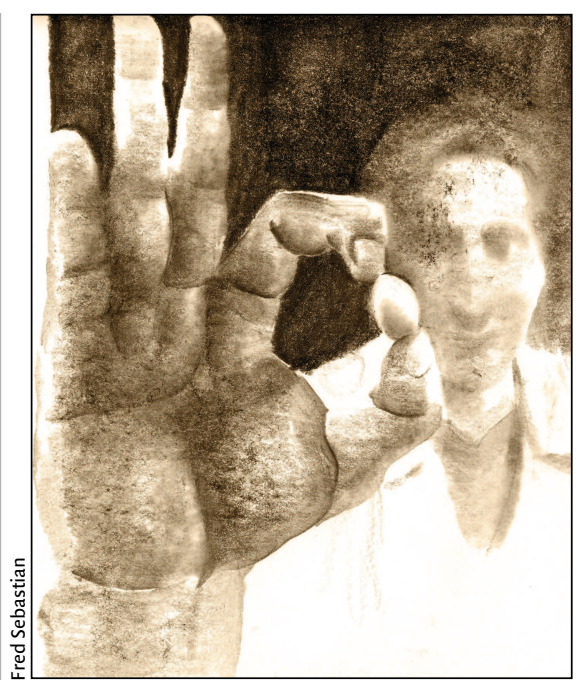

it and I would not give it to you anyway. It is against my principles, and I don't have to do anything I am uncomfortable with," he said loudly and proudly. The woman beside me nodded in agreement.

I remember being like Kevin with my own teenage optimism and unwavering sense that the world could be set right. I remember how I thought that my own convictions and personal example would be enough to inspire others. But, as I looked across the counter at this fresh-faced, straight-backed soldier of righteousness, what I really remembered was how to do a choke-hold.

As it happened, the counter was too wide to reach across. I settled on asking what his beliefs had to do with anything. Apparently quite a lot. According to Kevin, there is nothing unprofessional about placing personal conviction ahead of a woman's health care needs.

When I finally gave up he told me to go to Wal-Mart. I could be imagining it, but I got the impression that he was telling me Wal-Mart would be the only pharmacy to deal with "my kind of problem." It was getting late, the stores were closing, and Wal-Mart was a taxi ride across town.

At no time did anyone offer to speak to me privately about this. If I had been with my colleagues this second time, they would have discovered what I was asking for as surely as the other customers did. 
You get the point. If a reasonably articulate curmudgeon like myself cannot obtain emergency contraception, what chance does a worried, upset teenage girl have? Her choice would be to openly disclose intensely personal information, or to leave empty handed and humiliated.

The next day I went to the second of three pharmacies. I made my request and, on cue, the pharmacist was called over. Same routine, but with a twist; the pharmacist had not received the mandatory training. The pharmacy association, he said, insists that pharmacists receive special training on how to counsel women who ask for Plan B. The pharmacist had meant to sign up for the training but gosh, darn it all, he just hadn't got round to it.

I never made it to the Wal-Mart pharmacy. It was too far away, and I had no car.

\section{Barbara W. \\ Lawyer \\ Ottawa, Ont.}

Although this story recounts actual events, it does not purport to represent pharmacists or pharmacy assistants in general.

\section{One thousand words}

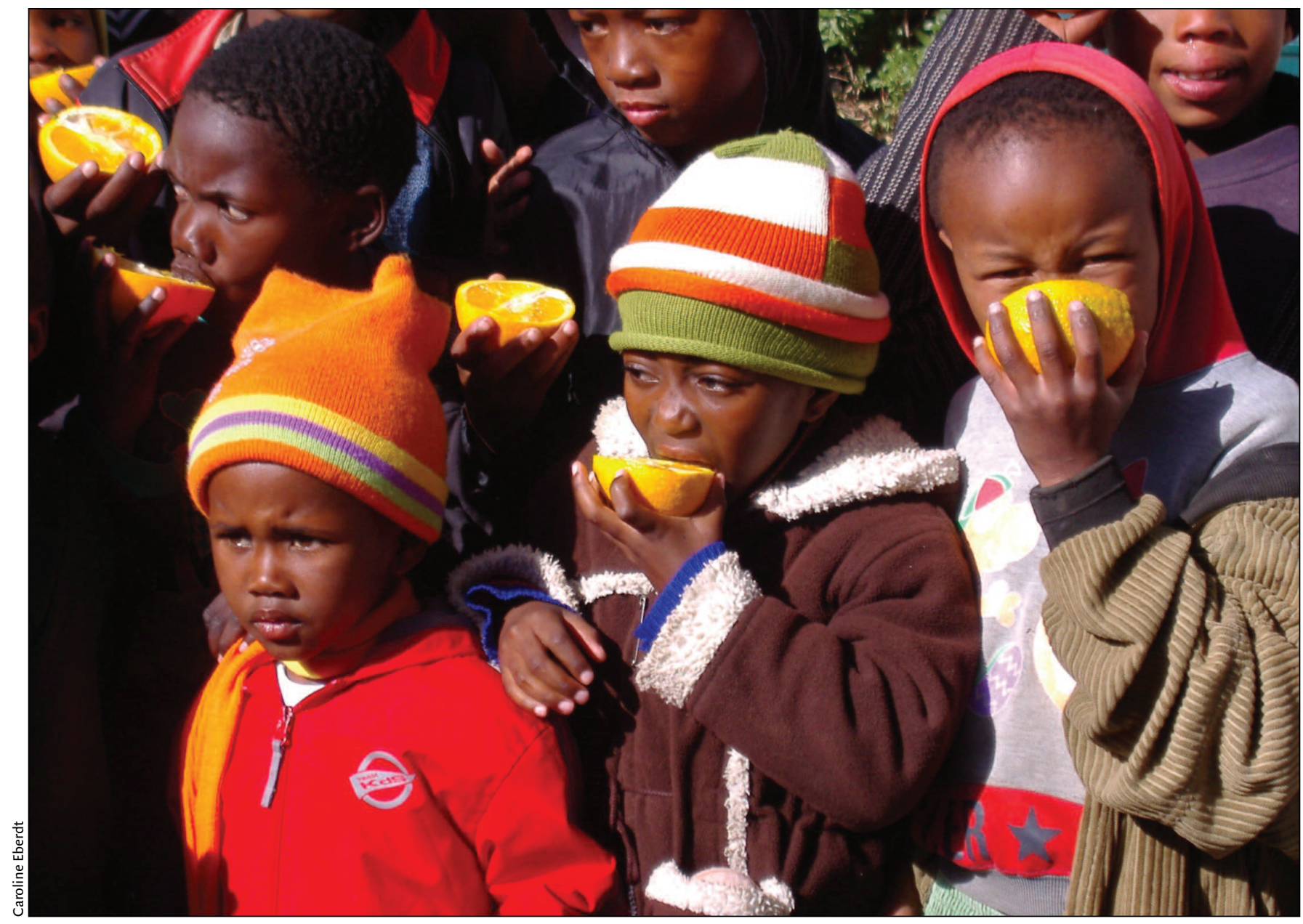

Midday snack at the nutritional centre, Rhini, Eastern Cape South Africa. This is the last of 3 photographs selected for publication in CMAJ from 6 finalists in a medical student photo contest and charity auction sponsored by McMaster University in 2005. This photograph, taken by Caroline Eberdt during an 8-week clinical elective, shows how preventive care can be delivered in many forms and reminds us that even the simplest interventions can be effective. The setting is South Africa, but it could be many places; anyone can identify with the effort of these children to deal with those bright oranges - awkward to eat, but tangy and delicious. One child is aware of the camera; the viewer is curious to know what holds the divided attention of the others. The photographer writes: "Rhini is a black township on the edges of Grahamstown, South Africa. Speaking in his home state, the Eastern Cape, Nelson Mandela called Rhini in 1996 'the most economically impoverished city in South Africa.' During this elective I was based at the public Settler's Hospital, working in obstetrics and primary care. Concurrently I conducted a small-scale research project examining the benefits and drawbacks to local organizational responses to gender-based violence and HIVIAIDS. Amid the tragedy that the AIDS epidemic has inflicted on the community, this nutritional centre, run by several community members, was a refreshing site of laughter and smiles." For the previous photos see CMAJ 2005;173(12):1514 and CMAJ 2006;174(1):71. 